\title{
System Design of Loss Fast Evaluation for Grassland Drought Disaster based on RS, GIS and GPS
}

\author{
Qiyun Ma, Jiquan Zhang*, Rui Wang, Si Ha, Meng Zhu, Danjun Li \\ School of Environment, Northeast Normal University, Institute of Natural Disaster Research, Northeast Normal
} University, Changchun 130024, China

\section{基于 3S 技术的草原牧区旱灾损失快速评估系统初探}

\author{
马齐云, 张继权 ${ }^{*}$, 王萑, 哈斯, 朱萌, 李丹君 \\ 东北师范大学环境学院, 东北师范大学自然灾害研究所, 长春 130024 , 中国
}

\begin{abstract}
Loss fast evaluation for grassland drought disaster is an important content of grassland natural disaster research. The basic situation and damage of grassland drought disaster in china were introduced in this paper. On that basis, the goal about loss fast evaluation for grassland drought disaster was proposed based on RS, GIS and GPS. This paper drew a program graph about loss fast evaluation, analyzed the grassland drought information spatial database and built the index system of loss fast evaluation for grassland drought disaster. Ultimately, this paper is aimed at providing scientific reference for decision-making and fast evaluation for loss of grassland drought disaster. At the same time, it's a realistic significance for the sustainable development of animal husbandry economy and ecological environment protection.
\end{abstract}

Key words: grassland; drought disaster; technology of RS, GIS and GPS; loss fast evaluation

\begin{abstract}
摘要
草原旱灾损失快速评估是草原自然灾害研究的重要 内容之一。本文简要介绍我国牧区干旱基本情况及其 危害, 在此基础上, 基于 $3 \mathrm{~S}$ 技术提出草原旱灾损失 快速评估系统设计的目标。本文绘制出草原旱灾损失 快速评估系统运行程序图, 并着重分析草原牧区旱情 综合信息空间数据库内容, 构建了牧区旱灾损失快速
\end{abstract}

*通讯作者: 张继权, Zhangjq022@nenu.edu.cn
评估指标体系。旨在为正确制定牧区抗早减灾决策和 快速评估草原早灾损失提供科学依据, 对牧区畜牧业 经济的可持续发展和生态环境保护具有现实意义。

关键词: 草原; 旱灾; $3 \mathrm{~S}$ 技术; 损失快速评估;

1. 引言

干旱是世界上危害最为严重的自然灾害之一, 居自然 灾害之首, 其出现次数多、持续时间长、影响范围广、 造成损失严重, 尤其是农牧业经济损失[1-3]。据测算, 全球每年因干旱造成的经济损失高达 60 亿 80 亿美 元, 远远超过了其他自然灾害 [4]。还有学者对中国 贫困县分布及干早分布进行了研究, 结论是中国贫困 县的分布和干旱的分布基本一致, 这表明干旱是造成 中国农村贫困的重要原因[5-6]。

牧区是我国牧业和半牧业旗县的统称, 主要以从 事牧业生产为主[7]。牧业经济是我国国民经济不可 缺少的重要部分, 但我国牧区, 尤其是北部和西部的 广大牧区地处干旱半干旱区域, 水资源缺乏, 生态环 境脆弱, 降水、径流年内、年际变率大, 时空分布不 均, 使得干旱发生频次多, 覆盖范围广, 持续时间长。 对草原牧区来说, 干旱的频繁发生和长期持续, 影响 地表和地下水资源的供应, 阻碍牧区牧草正常返青和 生长发育, 导致草地地上生物量减少 [8-9], 影响饲料 供应和人畜饮水, 进而影响区域畜牧业经济的可持续 发展, 制约着牧区生态环境的良性发展。随着全球气 候变暖, 中国北方牧区干旱化趋势明显[10-11], 对畜 牧业和草原生态环境所造成的经济损失也越来越大。

旱灾不仅对畜牧业造成重大损失, 还危及工业、 生态和牧民生活等方方面面。因此亟待对灾害发生前、 发生时及发生后进行及时、有效、快速的损失评估。 


\section{Risk Analysis and Crisis Response in Big Data Era (RAC-16)}

在灾害发生前，尤其是在可能出现特大干旱灾害时， 系统可以预测或粗略预估出灾害可能的范围和强度, 使管理决策人员做到心中有数, 做好防灾减灾准备工 作，防患于未然。当灾情刚刚发生时，系统应能快速 提供灾害的程度和范围、受灾对象和损失严重程度, 以利于及时采取减灾、救灾措施和灾后恢复的安排。 灾后评估是根据各有关部门通过各种方式提供的灾 情实况的报灾资料以及利用遥感、地理信息系统、全 球定位系统等等高新技术和设备来获取的信息资料, 分析报灾资料的可靠性，对灾前和灾中提出和实施的 各种防灾减灾方案进行分析和评估，以便提高防旱人 员今后进行减灾决策的能力[12]。当时如何快速实时 评价干旱灾害对草原牧区造成的系列损失, 国内外尚 无系统的研究。

当前研究中, 有关早灾影响的研究分为两类, 一 是利用统计方法对旱灾直接影响的计量、描述和相关 分析; 二是根据产业链关系，对旱灾相关损失的模拟 估算。二者均涉及农作物受早面积、成灾面积; 作物 减产数量、地区食物短缺数量和饥荒人口数量; 畜牧 业遭受损失情况; 干旱期地表水资源减少和地下水水 位下降状况, 机井报废数量; 人畜饮水困难程度; 土 壤、池塘干涸程度; 蝗虫灾害发生状况; 土地沙漠化 扩展面积与速率等方面[13-14]。总体而言, 前损失评 估大多集中于农业作物方面, 侧重降水与作物需水关 系、降水与农作物产量关系; 且大多数灾害损失评估 多是在灾害发生后进行研究, 实时性体现不强。而科 学、快速、准确的评估自然灾害所造成的损失, 是制 定减灾规划与决策的重要依据, 具有重要的意义。

本研究在综合考虑牧区干旱灾害频繁发生, 其早 灾损失较难准确定量评估的基础上，对如何利用 $3 \mathrm{~S}$ 技术及相关技术对草原牧区进行旱灾损失快速评估 进行探讨, 以期能对牧区草原旱灾损失研究有所禆益, 同时为草原牧区防旱减灾预案与牧区防旱减灾决策 系统建立提供科学可行的参考方法, 为草原牧区主动 防范干旱风险, 合理布局规划水资源提供相应的技术 手段。

\section{2. 牧区干旱灾害概况}

我国草原牧区主要分布在祖国大陆的北部和西部, 包
括牧业和半牧业地区。可大致分为内蒙古高原区、东 北山丘平原区、黄土高原区、西北内陆区、青藏高原 区和云贵高原区等六大区域[7]。牧区大部分处于内 陆地区, 降水较少, 呈显著的大陆性气候。地理环境 较差, 气候条件较为恶劣, 社会经济发展也较为缓慢, 畜牧业的发展受自然灾害及草地生产力的制约。由于 牧区发生较为缓慢, 且长期以来人们不合理利用草地 资源, 超载过牧, 更加之全球变化的影响, 使得草原 退化、沙化、盐碱化严重, 生态环境急剧恶化。

草原牧区干旱灾害的发生发展, 可归纳为以下几 个特点：（1）普遍性。干旱灾害普遍发生在我国各大 牧区境内, 据文献资料统计, 近 40 年, 仅甘肃、宁 夏、青海、内蒙古等牧区发生各类干旱的就有 13 年 [15];（2）连续性。牧区干旱灾害的主要特点就是旱 灾的发生容易产生连年干旱和连季干旱, 且此情况较 为普遍; (3) 周期性。干旱的发生具有一定的周期性, 如内蒙古干旱的发生就存在着“十年七春旱, 五年一 特大春旱” 的规律; (4) 滞后性。干旱对畜牧业产生 的危害, 是经过一定的时间累积延后表现出来的, 总 是落后于干旱开始的时间 [7];（5）波及范围广。旱 灾的发生并不只是小范围内部的损失, 区别于地震等 自然灾害, 干旱在草原牧区的发生, 常常会造成大范 围的损失。

由于长期干旱等自然和认为因素的综合作用, 旱 灾对牧区经济、人畜饮水、草原环境及社会安定等各 方面，均造成了严重的损害。因此有关草原牧区旱灾 损失快速评估研究的开展, 极为必要。

\section{3. 系统总体设计}

草原牧区旱灾损失快速评估系统建立的核心, 在于快 速的评定草原早灾发生发展对草原牧区造成的损失, 为牧区抗旱减灾、物资调配提供科学的参考依据。核 心在于一个“快”字, 本系统建立以地理信息系统、 遥感和全球定位系统 (3S 技术) 为主要技术平台, 在实时高时空分辨率遥感数据的支持下, 通过遥感数 据的定量研究[16-17], 提取与旱灾形成发展相关的空 间因子与属性因子, 提取出牧区草地资源受灾范围, 通过与牧区早灾损失指标体系的分析, 实现精细化干 旱动态监测, 进而达到对干旱损失快速评估的目的。 
Risk Analysis and Crisis Response in Big Data Era (RAC-16)

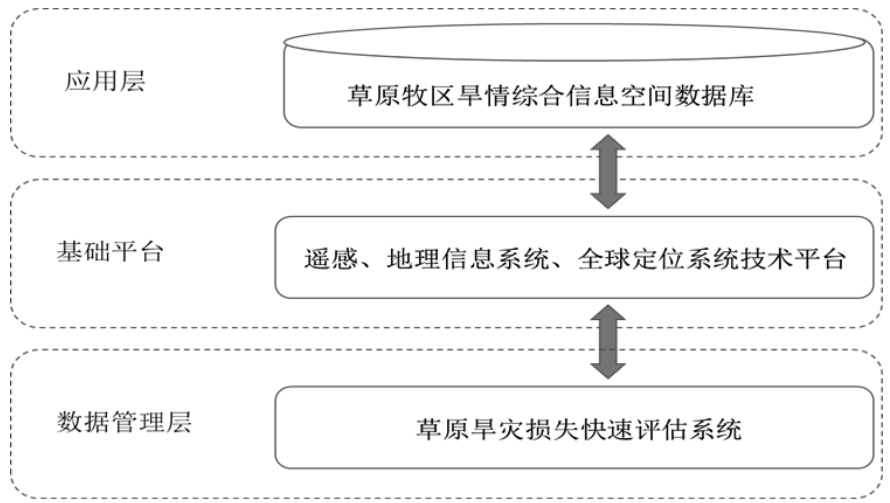

图 1 系统总体设计

\section{1. 系统设计目标}

草原牧区旱灾损失快速评估系统主要实现的目标有：

（1）实现牧区旱灾发生前、灾中及灾后各类信 息快速的采集、存储、处理、检索、归纳、管理、分 析和发布;

(2) 向国家抗旱减灾部门提供准确的受灾信息, 为政府提供合理可行的控灾方案, 为防旱物资调配提 供科学依据;

（3）集成牧区其他灾害信息系统，实现草原牧 区防灾减灾信息化、网络化。

\section{2. 系统设计牧区旱灾损失快速评估路线}

根据草原牧区旱灾损失快速评估系统建设目标和应 用功能，建立系统技术路线如图 2 所示。建设旱灾损 失快速评估系统的首要任务是建立区域旱情空间数 据库, 该数据库是整个系统的基础, 可以为灾前的风 险识别和分析提供基础数据, 灾害发生后也可以实现 及时更新和补充最新的数据。

\subsection{1. 草原牧区旱情综合信息空间数据库}

旱情综合信息空间数据库主要包括各类草原牧区的 基础数据, 主要包括有: 各级行政区划图、全要素地 形图数据、DEM、土壤类型、植被类型、土地利用、 水文数据、居民点数据、道路交通数据、经济社会数 据、草地资源数据、气象数据、草地资源权属数据、 人口数据、历史草原灾害损失数据、遥感影像数据等 等。此外, 为了达到实时快速评估干旱发生发展情况, 还须包括: 实时的遥感影像数据（地表温度、植被冠 层温度、NPP 数据等等)、气象台站提供的实时气象 基础资料、草原牧区土壤墑情实时监测数据、牧草生 长发育期观测数据。通过该基础数据数据库与“ $3 \mathrm{~S}^{\text {” }}$
技术结合, 可实现受灾牧区范围的及时预警, 并快速 识别并提取出牧区受灾范围, 图 3 是 GIS 技术应用 的示例。

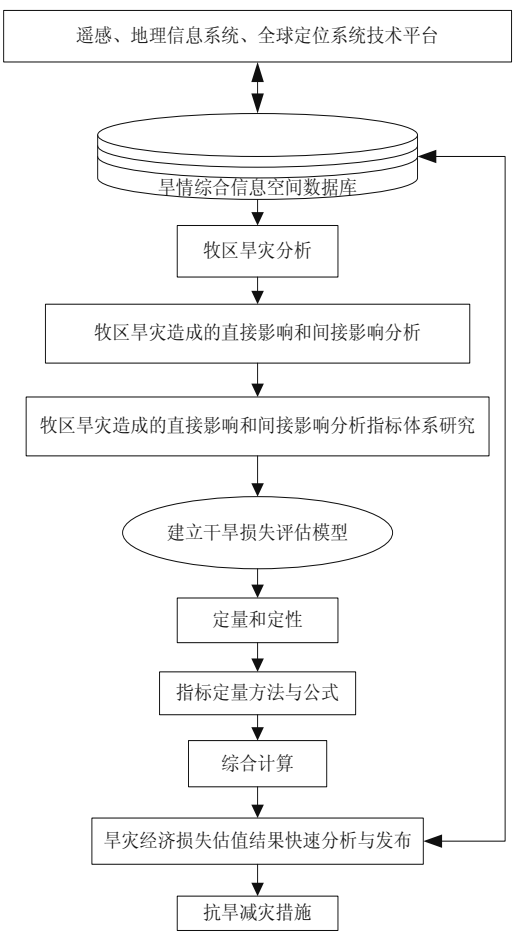

图 2 牧区旱灾损失快速评估运行路线图 
Risk Analysis and Crisis Response in Big Data Era (RAC-16)

\subsection{2. 牧区旱灾损失快速评估指标体系构建}

旱灾损失对牧区造成的损失是多方面的, 既有经济方 面的影响, 又有生态方面的影响, 还有社会方面的影 响, 可分为直接损失与间接损失两种。由于干旱对牧 区产生的影响具有滞后性, 所以相关间接损失较难估 量。本研究综合考虑干旱灾害对牧区造成的牧草损失、 畜产品损失、水资源损失及生态环境损失, 根据数据 的可获取程度, 构建干旱损失快速评估指标体系, 如 图 3 所示。根据本文提出的牧区旱灾损失快速评估指 标体系, 可以在灾前初步评价出灾害受损范围, 同时
预估出损失程度, 进而采取相应的抗早减灾政策; 在 旱灾发生过程中, 也可根据灾害发生情况, 进行灾害 损失的快速评估; 在灾害发生后, 既可以评估本次旱 灾造成的实时损失, 又可以加入草原牧区早情综合信 息数据库中, 为今后灾害损失评定提供详实的数据支 撑。需要指出的是, 该损失指标体系中, 定量计算的 指标均可根据先关现有方法, 转换成实际市场价值, 进行经济估值, 而损失定性分析中需要根据灾害发生 的实际情况进行评定。

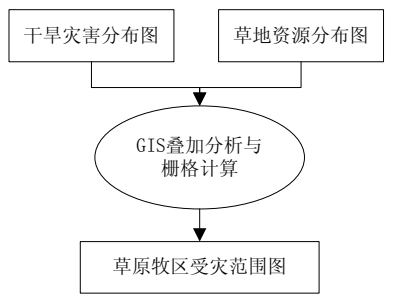

图 3 GIS 技术提取草原牧区受灾范围

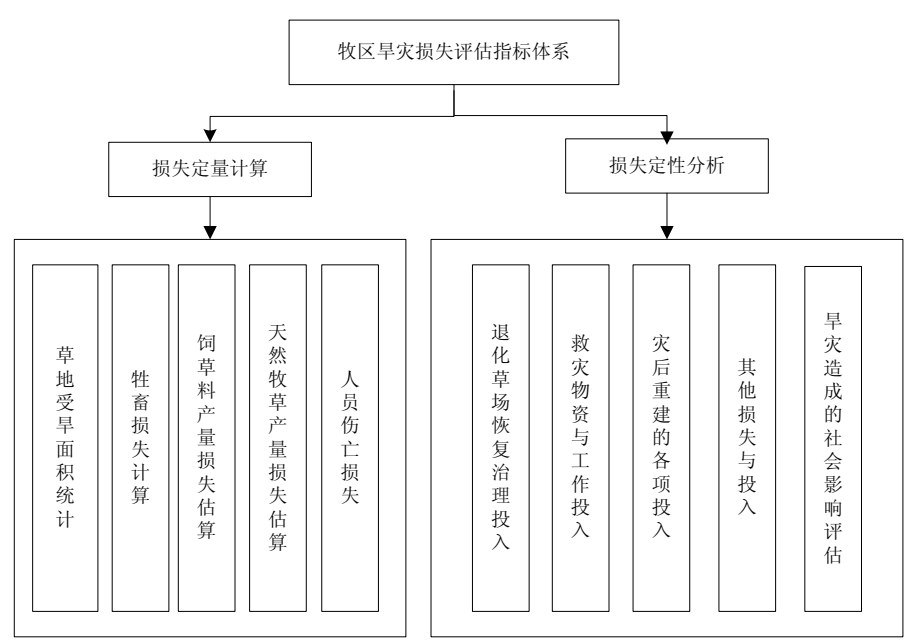

图 4 草原牧区旱灾损失快速评估指标体系

\section{4. 结语}

本文虽然提出了草原牧区早灾损失快速评估系统的 建立，但也有一些问题需要逐步完善，如各牧区基础 信息共享机制上, 仍需进一步加强; 如何将灾害损失
评估结果逐步精准化, 也是下一步要努力的方向。牧 区早灾损失涉及方面较广, 本文选取的旱灾损失指标 体系还需不断完善。

旱灾作为社会问题正旱灾作为社会问题正日益 引起人们的关注, 同时它也是一个经济问题, 正是由 
Risk Analysis and Crisis Response in Big Data Era (RAC-16)

于旱灾造成了数额巨大的经济损失而使社会生活受 到不同程度的破坏，从而体现出其社会性 $[12,18]$ 。快 速评估干旱灾害对牧区造成的损失, 对于了解旱灾危 害, 进行牧区水资源分配[19]以及制定减灾方案具有 重要的现实意义, 符合国家防灾减灾的根据需求。草 原牧区早灾损失快速评估系统的建立, 将为牧区管理 部门及牧民提供科学的服务, 也将提高草原牧区自身 防灾减灾的综合能力。

\section{Acknowledgement}

This study was financially supported by the National Science and Technology Pillar Program during the 12th Five-Year Plan Period No. 2013BAK05B02 and No. 2013BAK05B01.

\section{致谢}

本研究得到了“十二五”国家科技支撑项目 （2013BAK05B02 和 2013BAK05B01）的资助。

\section{5. 参考文献}

[1] 张继权, 李宁. 主要气象灾害风险评价与管理的 数量化方法及其应用. 北京: 北京师范大学出版 社, 2007: 216-217.

[2] Guan Y, Zheng F, Zhang P, et al. Spatial and temporal changes of meteorological disasters in China during 1950-2013. Natural Hazards. 2015, 75(3): 2607-2623.

[3] Mishra A K, Singh V P. A review of drought concepts. Journal of Hydrology, 2010, 391(1-2): 202-216.

[4] Wilhite D A. Drought as a natural hazard: Concepts and definitions//Wilhite D A. ed. Drought: A Global Assessment. London \& New York: Routledge, 2000:3-18.

[5]颜亮东, 李林, 刘义花. 青海牧区干旱、雪灾灾害 损失综合评估技术研究. 冰川冻土. 2013(03): 662-680.

[6] 李芬, 于文金, 张建新, 等. 干旱灾害评估研究 进展. 地理科学进展, 2011，30(7): 891-898.

[7]杨爱荣. 基于 GIS 技术的牧区防旱减灾辅助决策 系统研建. 北京林业大学, 2004.

[8]GB29366-2012 北方牧区草原干早等级. 北京: 中 国标准出版社, 2013.

[9]Frank D A. Drought effects on above- and belowground production of a grazed temperate grassland ecosystem. Oecologia, 2007, 152(1): 131-139.

[10]李兴华, 陈素华. 内蒙古草地干旱损失评估方法 研究. 草业科学, 2012，29(7): 1033-1038.

[11]Wang W, Zhu Y, Xu R, et al. Drought severity change in China during 1961-2012 indicated by SPI and SPEI. Natural Hazards, 2015, 75(3): 2437-2451.

[12]杨恒喜, 史正涛, 谷晓梅. $3 \mathrm{~S}$ 技术支持下的云南 旱灾损失实时评价研究. 环境研究与监测. 2010(02): 9-14.

[13]杨丽萍, 韩德彪, 姜宝法. 干旱对人类健康影响 的研究进展. 环境与健康杂志, 2013, 30(5): 453-455

[14]徐国昌. 干旱减灾问题的回顾与思考. 干早气象, 2012, 30(4): 89-496.

[15]李晶, 王耀强, 屈忠义, 等. 内蒙古自治区干旱 灾害时空分布特征及区划. 干早地区农业研究. 2010(05): 266-272.

[16]苏文荣, 张晓显. 干旱遥感监测预警评估研究综 述. 宁夏农林科技. 2007(01): 45-48.

[17]覃志豪, 高禁芳, 秦晓敏, 等. 农业旱灾监测中 的地表温度遥感反演方法--以 MODIS 数据为例. 自然灾害学报. 2005, 14(4): 64-71.

[18]李洁, 宁大同, 程红光, 等. 基于 $3 \mathrm{~S}$ 技术的干旱 灾害评估研究进展。中国农业气象. 2005(01): 50-53.

[19]Zhang R, Zou H, Hong M, et al. Risk analysis of water resources crisis in the lancang-mekong river drainage basin under the background of climate change. Journal of Risk Analysis and Crisis Response, 2(3): 209-213, 2012. 